\title{
The In vitro effects of Zidovudine (an antiretroviral Drug) on Human erythrocyte Haemoglobin -S gelation
}

\author{
*1. Okonkwo, C.O. and ${ }^{2}$ Uwakwe A.A \\ 1 Biochemistry Department, College of Natural and Applied Sciences, Michael Okpara University of \\ Agriculture Umudike, Abia State. Nigeria. \\ 2Department of Biochemistry, Faculty of Sciences, University of Port-Harcourt chioba, Rivers State. Nigeria.
}

\begin{abstract}
Zidovudine (AZT) is a nucleoside analog, a reverse transcriptase inhibitor (NRTI) and a type of antiretroviral drug used for the treatment of HIV/AIDS. The in vitro action of zidovudine $(\mathrm{mg} / \mathrm{ml})$ on sickle red blood cell haemoglobin showed a non-significant $(P>0.05)$ decreases in Haemoglobin $S$ gelation. There was significant $(P<0.05)$ decrease in relative polymerization rate with corresponding significant $(P<0.05)$ increase in the relative percentage inhibition which was dose dependent, Zidovudine therefore reduces the rate of haemoglobin-S gelation in sickle cell patients. This makes it a promising antiretroviral medicine for sickle cell patients of HIV and AIDS.
\end{abstract}

Keywords: zidovudine, nucleoside analog, reverse transcriptase, inhibitor, antiretroviral, gelation, polymerization

\section{Introduction}

HIV (Human Immune deficiency virus) is a lent virus (a member of the retrovirus family) that causes Acquired Immunodeficiency Syndrome (AIDS). It is a condition in humans in which the immune system begins to fail, leading to life-threatening opportunistic infections. (Douek et al., 2009). From its discovery in 19812006, AIDS has killed more than 25 million people worldwide (Levin et al., 2010). HIV infects about $0.6 \%$ of the world's population. (Greener.,2002)). According to current estimates, HIV is set to infect 90million people in Africa resulting in a minimum estimate of 18 million orphans (Morgan et al., 2002). HIV infects primarily vital cells in the human immune system such as helper $\mathrm{T}$ cell (specifically CD4+ $\mathrm{T}$ cells), macrophages and dendritic cells. HIV infection leads to low levels of CD4+ T cells, When CD4+ T cell members decline below a critical level, cell-mediated immunity is lost, and the body becomes progressively more susceptible to opportunistic infections. Most untreated people infected with HIV eventually develop AIDS. These individuals die mostly from opportunistic infections or malignancies associated with the progressive failure of the immune system (Klein and Abigail. 2010).

Antiretroviral drugs are medications for the treatment of infection by retroviruses, primarily HIV (Botes ., 2003). Antiretroviral treatment reduces both the mortality rate and the morbidity of HIV infection and increases the life expectancy of infected people even after HIV has progressed to diagnosable AIDS (Kitahata et al ., 2009). Although ART is not a cure for HIV/AIDS, it can significantly prolong and improve the lives of HIV-infected people (Hicks et al., 2003). Antiretrovirals slow down the production of HIV and give the body a chance to build up its CD4+ cell count which in turn helps the body fight against opportunistic infections (Henry ., 2000)

Zidovune (INN) or azidothymidine (AZT) is a nucleoside analog, reverse transcriptase inhibitor (NRTI), a type of antiretroviral drug used for the treatment of HIV and AIDS. It is an analog of thymidine (Izzedine et al., 2001). Zidovudine was the first approved treatment for HIV sold under the names Retrovir and Retrovis (Broder., 2009). The cellular DNA polymerase used by mitochondria to replicate is more sensitive to the inhibitory effects of Zidovudine accounting for its toxic effects on cardiac and skeletal muscle, causing myositis (Cazzaline et al., 2001). Common side effects of Zidovudine include: nausea, headache, changes in body fat and discoloration of fingernails and toenails. More severe side effects include: anemia and bone marrow suppression which can be overcome using erythropoietin or darbepoetin treatments respectively (Brinkman et al., 1998).The purpose of this work therefore is to ascertain the possible side effects of zidovudine on the liver, erythrocyte membrane elasticity and oxygen transport in the body.

Sickle cell anemia is a blood disorder that affects haemoglobin; the protein found in red blood cells that carry oxygen throughout the body. Sickle cell anemia occurs when a person inherits two abnormal genes (one from each parent) that cause their RBCs to change shape instead of being flexible and disc-shaped. These cells are stiff and curved in shape. The shape is similar to a crescent moon. The sickled red blood cells are fragile and prone to rupture. When the number of red blood cells decreases from rupture (hemolysis), anemia becomes the result. The irregular sickled cells don't move easily through the blood vessels. They are stiff and sticky and tend 
to get stuck in the blood vessels. The clumps of sickle cells block blood flow in the blood vessels in the limbs and organs. This causes pain, serious infections and organ damage.

During reduced oxygen state, $\mathrm{HbS}$ undergo a certain change known as gelation, this causes the erythrocyte to become rigidified and sickle shaped. At fixed temperature and $\mathrm{P}^{\mathrm{H}}$, along with fixed ionic strength and organic phosphate concentration, gelation is dependent upon the concentration of the Hemoglobin. It has been shown that there is formation of small aggregates in the doexy-sickle haemoglobin solution before gelation. When cells containing $\mathrm{HbS}$ are suddenly deoxygenated, a short delay occurs before the cell begins to transform gradually into the typical sickle shape. This delay is due to molecular condensation when fiber formation occurs. This delay time of gelation is used to determine the probability of sickling inside capillaries. In haemoglobin-S, the polar glutamate residue is replaced with a non polar Valine residue. This generates a "sticky patch" on the surface of the $\beta$-chain. Haemoglobin-S can also bind to the complimentary patch on another deoxygenated haemoglobin molecule, causing a polymerization of deoxyhaemoglobin, which forms long fibrous precipitations that mechanically distorts sickle red cells causing lysis and multiple secondary chronic effects. As sickle polymers are formed during deoxygenation, the red blood cells become rigid and as a result may obstruct capillary blood flow. The rate at which polymerization occurs depends primarily on the intracellular concentration of $\mathrm{HbS}$ and the extent of deoxygenation. If polymerizatrion occurs before the erythrocytes escapes the narrow-bore capillary, obstruction may occur resulting in local tissues hypoxia, further deoxygenation and further sickling. This vicious cycle may result in the amplification of microscopic obstruction into a larger area of infarction. The oxygen depleted sickle cycle is ordinarily reversible. However, the membrane of SS erythrocytes may become sufficiently damaged so that the cells loose potassium and water which will lead to the formation of irreversible sickle forms. Proportion of irreversible sickle cells varies considerably among homozygous sicklers and is not correlated with chemical severity.

\section{Chemicals}

\section{Materials And Methods}

Except otherwise stated, all the chemicals used were of analytical grade and were manufactured by Randox chemical laboratories and BDH chemicals limited, both in England. Zidovudine was purchased from Ariara International market Aba, Abia state and was manufactured by Vivin Laboratories Ltd (India).

\section{Blood Sample collection from Human}

For the determination of Haemoglobin-S gelation rate, fresh blood samples were collected from fifteen confirmed sickle cell disease patients with their consent. Exactly $0.2 \mathrm{ml}$ portions of HbSS blood sample was collected into citrate tubes, erythrocytes were isolated from the blood samples by centrifugation at 1500 rotations per minute for 15 minutes followed by careful siphoning of the plasma with Pasteur pipette, the erythrocyte were by repeated inversion suspended in a volume of isotonic saline $(0.9 \% \mathrm{NaCL})$ equivalent to the volume of the siphoned plasma. The erythrocyte suspension was then thawed to produce a hemolysate for the haemoglobin polymerization experiment.

\section{Determination of Haemoglobin-S-gelation}

Haemoglobin-S-gelation was determined by the method described by Noguchi and Schecter (1977) which reveals that under very low oxygen tension, haemoglobin $S$ polymerises. This suggests intracellular gelation as the basis of sickling of erythrocytes.. Hb $\mathrm{S}$ gelation was induced by subjecting solution of the Haemoglobin $\mathrm{S}$ to hypoxia using $2 \%$ sodium metabisulphite. The gelation was monitored spectrophotometrically at $700 \mathrm{~nm}$.

\section{Statistical analysis}

Data was analysed by the use of a one way analysis of variance (ANOVA). Means were compared by the Duncan's (1957) multiple range test and significance was accepted at $95 \%$ confidence level. $(p=0.05)$

III. Result

Table 1 Human haemoglobin S gelation Rate

Hb gelation rate ( $\triangle O D / \mathrm{min})$

\begin{tabular}{|l|l|l|l|}
\hline Zidovudine $(\mathrm{mg} / \mathrm{ml})$ & Hb gelation rate $(\Delta \mathrm{OD} / \mathrm{min})$ & Relative \% polymerization & Relative \% inhibition \\
\hline 0.00 & $0.030 \pm 0.00^{\mathrm{a}}$ & $100 \pm 0.0$ & $0.00 \pm 0.0$ \\
\hline 0.20 & $0.017 \pm 0.00^{\mathrm{a}}$ & $56.1 \pm 0.0^{\mathrm{a}}$ & $43.9 \pm 0.1^{\mathrm{c}}$ \\
\hline 0.40 & $0.013 \pm 0.00^{\mathrm{a}}$ & $42.9 \pm 0.2^{\mathrm{b}}$ & $57.1 \pm 0.2^{\mathrm{b}}$ \\
\hline 0.60 & $0.010 \pm 0.00^{\mathrm{a}}$ & $33.0 \pm 0.1^{\mathrm{c}}$ & $67.0 \pm 0.1^{\mathrm{a}}$ \\
\hline 0.80 & $0.009 \pm 0.00^{\mathrm{a}}$ & $29.7 \pm 0.2^{\mathrm{c}}$ & $70.3 \pm 0.1^{\mathrm{a}}$ \\
\hline
\end{tabular}


Values represent means \pm SEM of triplicate determinations. Means with the same superscript along the same row are not significantly different at $95 \%$ confidence level $(\mathrm{P}<0.05)$.

\section{Figure 1}

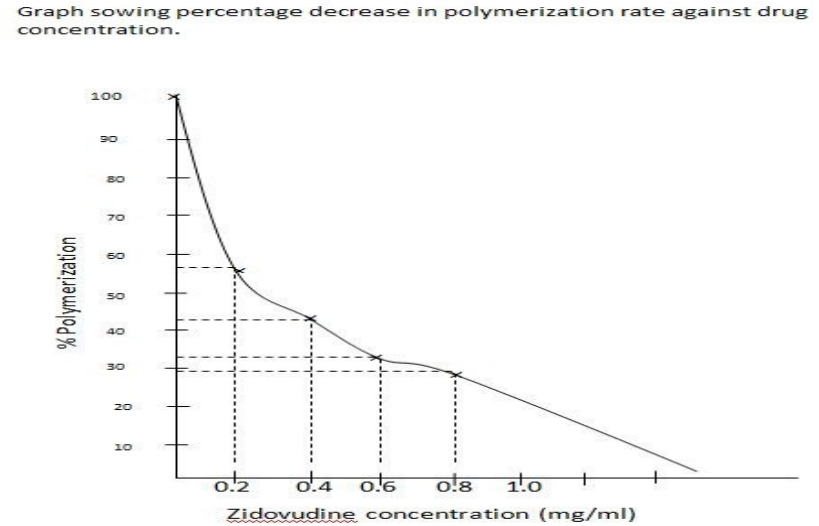

There were non-significant $(\mathrm{P}>0.05)$ decreases in Haemoglobin $\mathrm{S}$ gelation with increasing drug concentration. Also significant $(\mathrm{P}<0.05)$ decrease in relative polymerization rate was observed with corresponding significant $(\mathrm{P}<0.05)$ increase in the relative percentage inhibition as the drug concentration increased from 0.02 to $0.08 / \mathrm{ml}$ zidovudine.

\section{Discussion}

The decreases in Haemoglobin S gelation rate and percentage polymerization rate, as well as the increased inhibition rates of polymerization observed from this study, indicate that zidovudine may be good for sickle cell patients with HIV. Haemoglobin S erythrocytes are more prone to lysis (increased fragility) as a result of increased polymerization (gelation) with consequent generation of fibrous haemoglobin S molecules at states of hypoxia (Chien., 1977,Perutz et al 1951 ).This phenomenon is the root cause of all biochemical and physiological problems suffered by sickle cell (Hb SS) patients. The result from this work showed that zidovudine inhibits Haemoglobin S- gelation rate in a concentration dependent manner. The administration of zidovudine to sickle cell patients may therefore pose no threat to their health status as far as sickling is concerned. Since $\mathrm{Hb} \mathrm{S}$ are more prone to lysis(increased fragility) as a result of increased polymerization, Zidovudine may also reduce the lysis(fragility) of $\mathrm{Hb} \mathrm{S}$ erythrocytes, which is a big plus for sickle cell patients with HIV infection.

\section{Conclusion}

The effect of zidovudine on the gelation rates and percentage polymerization of HbSS shows that it is a very promising drug for the treatment of HIV in sickle cell patients. Zidovudine should therefore be encouraged in the treatment of HIV in sickle cell patients.

\section{References}

[1]. Botes M.E. Antiretroviral therapy: pharmacology. In Disease Review, p334-341, Johnnic Publishing, 2003.

[2]. Brinkman K, Hofstede H.Buraer D.M, Smeitink I and Koopmans P.P (1998). Adverse effects of reverse transcriptase inhibitors: mitochondrial toxicity as common pathway. AIDS 12:1735-1744.

[3]. Broder, S. (2009). "The development of antiretroviral therapy and its impact on the HIV-1/AIDS pandemic". Antiviral research 85 (1): $1-2$.

[4]. Cazzalini O, Lazze M.C and Lamele L (2001). Early effects of AZT on mitochondrial functions in the absence of mitochondrial DNA depletion in rat myotubes. Biochem Pharmacol 62:893-902.

[5]. Chien, S (1977) Rheology of Sickle Cells and Erythrocyte Content of Blood Cells 3: (698-705)

[6]. Douek D.C,Roederer M and Koup R.A (2009). "Emerging concepts in the immunopathogenesis of AIDS". Annu. Rev. Med. 60: 471-84.

[7]. Duncan B.D (1957) .Multiple range tests for correlated and heteroscedastic means. Biometrics 13:359-364.

[8]. Greener, R. (2002). "AIDS and macroeconomic impact". In S, Forsyth (ed.). State of The Art:AIDS and Economics. IAEN. pp. 4955.

[9]. Henry C.A (2000).Semitogenesis in Zebrafish.Ph.D Thesis University of Washington.

[10]. Hicks L.M,Cahoon R.E;Bonner E.R, Rirard R.S,Sheffield J and Jez J.M (2003). Current management challenges in HIV: Tolerability of Antiretrovirals and metabolic complications. aids patient care and STDs. 17(5),

[11]. Huisma T.H.J (1996) A syllabus of Human Hb Variants. Globin Gene Server.Pennysylvania State U niversity pp67.

[12]. Izzedine H, Vincent Launay-Vacher, Alain Baumelou, and Gilbert Deray (2001) Pharmacokinetics of nevirapine in haemodialysis.Nephrol Dial Transplant. 16:192-19

[13]. Kitahata M.M, Gange S.J and Abraham A.G, (2009). "Effect of early versus deferred antiretroviral therapy for HIV on survival". N. Engl. J. Med. 360 (18): 1815-26. 
[14]. Klein Leichman and Abigail (2010). "On the HIV warpath". Israel 21c Innovation News Service. http://israel21 c.org/201010038374/health/on-the-hiv-warpath. Retrieved 11 October 2010.

[15]. Levin, Aviad; Hayouka, Zvi; Friedler, Assaf; Loyter and Abraham (2010). "Specific eradication of HIV-1 from infected cultured cells". AIDS Research and Therapy 7(31): 31.

[16]. Morgan D, Mahe C, Mayanja B, Okongo JM, Lubega R, Whitworth JA (2002). "HIV-1 infection in rural Africa: is there a difference in median time to AIDS and survival compared with that in industrialized countries?". AIDS 16 (4): 597-632.

[17]. Noguchi, C.T and Schecter, A.N.(1977).Effects of Amino acid on Gelation KLinetics and Solubhility of Sickle Haemoglobin,Biochem.Biophys.Res Commune:74(637-642).

[18]. Perutz,M.F and Mitchison,J.M., (1950). State of Haemoglobin in Sickle Cell Anaemia.Nature:166(677). 